\title{
Residual Stress Generation at Crack Tip under Thermomechanical Effects of Aluminum Alloy 2024-T3: Numerical Modelisation
}

\author{
Tayeb Kebir ${ }^{*}$, Mohamed Benguediab ${ }^{1}$, Mohamed Bouamama ${ }^{2}$, Zine El Abidine Harchouche $^{1}$ \\ ${ }^{1}$ Laboratory of Materials and Systems Reactive, Department of Mechanical Engineering, Faculty of Technology, University of \\ Sidi Bel Abbes 22000, Algeria \\ ${ }^{2}$ Laboratory Mechanics of Structures and Solids, Department of Mechanical Engineering, Faculty of Technology, University of \\ Sidi Bel Abbes 22000, Algeria
}

Corresponding Author Email: kebirtayeb@live.fr

https://doi.org/10.18280/acsm.440108

Received: 2 November 2019

Accepted: 26 December 2019

\section{Keywords:}

residual stress, numerical modelisation, plastic strain, thermomechanical, crack tip

\begin{abstract}
The residual stresses which result from the manufacture are present in the mechanical part with absence of any external force, but also they can be generated by various procedures. These stresses are the result of incompatibilities of deformation related to the heterogeneity of the plastic strain. Therefore, as the crack propagated in the residual stress field, the distribution of residual stresses is changed. The purpose of this work is to generate the thermomechanical residual stresses on along direction of crack propagation using a numerical simulation by Ansys software. This numerical approach allows us to evaluate the thermomechanical relaxation of the compressive residual stresses induced by plastic strain at crack tip.
\end{abstract}

\section{INTRODUCTION}

The residual stresses are stresses that remain in a solid material after the original cause of the stresses has been removed. Manufacturing processes are the most common causes of residual stress. Virtually all manufacturing and fabricating processes such as casting, welding, machining, molding, heat treatment, plastic deformation during bending, rolling or forging introduce residual stresses into the manufactured object. Therefore, the residual stress could be caused by localized yielding of the material, because of a sharp notch or from certain surface treatments like shot peening or surface hardening $[1,2]$. So, the residual stresses and thermal distortion are a common phenomenon observed in any welding method [3]. Another work of Lingamanaik et al. [4] has demonstrated that altering the quenching parameters (heat transfer coefficients, quenching duration and quenching locations) can promote favorable compressive residual stresses in the rim of rail wheels.

In addition, there are many techniques used to measure residual stresses, which are broadly categorized into destructive, semi-destructive and non-destructive techniques, are studied by many others $[5,6]$. The microstructure and $\mathrm{X}$ ray tests carried out on tubular specimen revealed the residual stresses on the inner surface due to machining surface features $[7,8]$.

Furthermore, the explicit formula to predict the thermomechanical relaxation of a shot peening residual stress are obtained by Huang et al. [9]. So, Wang et al. [10] have proposed analytical model can reflect the residual stress distribution on welded joints after shot peening process.

The relaxation of residual stresses due to thermal loading are caused by the decrease of the yield stress of the target with increased temperature, have been studied by Stranart et al. [11,
12]. Also, the grinding process is currently used for most of the parts requiring good precision, a model for numerical simulation of grinding is presented by Brosse et al. [13] taking into account the thermomechanical residual stresses.

The influence of thermomechanical methods on the development of the final distortions and residual stresses is analyzed, it is well-known that thermomechanical the substrate is an effective method to reduce the distortion and residual stresses in additive manufacturing [14]. Also, the influence of initial welding residual stress on the stress distribution after shot peening was analyzed and discussed by Wang et al. [10]. The effects of thickness geometric and thermal treatment on residual stress were also discussed by Song et al. [15, 16]. So, Molano et al. [17] have studied thermomechanical treatment effects on residual stress generation. Another, the effect of thermal properties and weld efficiency on residual stresses in welding have been studies by Armentani et al. [18, 19]. However, the fatigue strength improvement is due to the combined effect of residual compressive stress and the work hardening [20]. The effect of processing condition on thermal residual stress development in the build part, also that the processing conditions could be optimized for minimizing thermal residual stress, have been studied by Panda et al. [21]

So, as many researchers have been carried out on the effect of residual stresses on fatigue behaviors, the studies on the numerical modeling of residual stress redistribution due to fatigue crack propagation are relatively insufficient [22, 23]. Thus, the effects of weld residual stresses on fatigue crack growth (FCG), both parallel and perpendicular to Aluminum friction stir welds were investigated by many others [24-28].

Thermal residual stresses are primarily due to differential expansion when a metal is heated or cooled. The two factors that control this are thermal treatment (heating or cooling) and 
restraint. Both the thermal treatment and restraint of the component must be present to generate residual stresses. So, the residual stresses can be present in any mechanical structure because of many causes. The present work is a numerical approach of thermomechanical effect which produces plastic deformations using mechanical behavior proportional for each temperature of Aluminum alloy 2024-T3. If the applied loading greater the yield stress leading after unloading a field of residual stresses at crack tip. This work allows us to seem the temperature and plastic deformation effects on material test. The finite element method has been used for numerical modeling by software Abaqus.

\section{NUMERICAL MODELISATION}

The numerical approach of the residual stress generation is carried out using the Finite Element Method. The analysis was performed by the commercial FE code ABAQUS. The study for the distribution of residual stresses along the direction of the crack propagation in a compact tension (CT) specimen given in ASTM E647, with the dimension of the width $\mathrm{W}=$ $75 \mathrm{~mm}$ and thickness $\mathrm{t}=6 \mathrm{~mm}$, see Figure 1 . It was meshed by means of eight-node brick solid elements to improve the accuracy of the FE solutions.

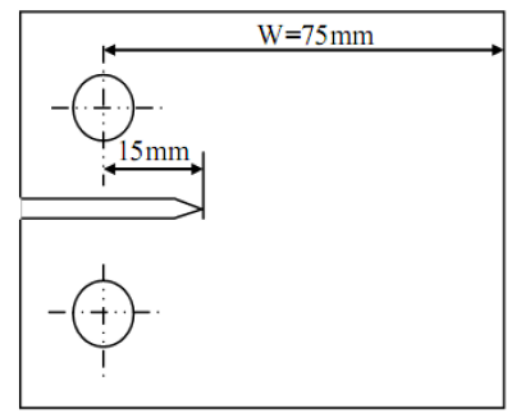

Figure 1. Compact tension (CT) Specimen test (ASTM E647)

Using the Aluminum alloy 2024-T3 which the mechanical properties as a function of temperature are obtained by Lipski et al. [29], see the Figure 2, as allows us to make the numerical simulation of the residual stresses under the thermomechanical effects.

The numerical simulation is done because the rate loading of the applied stress per yield stress $(\mathrm{R}=\sigma a p p / \sigma y)$ greater one. That is to say, for generate the residual stress field; the applied force must exceed the yield stress $\sigma y$ to elastic-plastic behavior then unloading or relaxation. Therefore, the rest of compression stress at crack tip of CT specimen is the residual stress.

In this work, we found four variation of the rate loading $(\mathrm{R}=$ $1.01,1.05,1.10$ and 1.15). For each rate, the mechanical loadings are carried out proportional to each mechanical behavior at known temperatures and vary from $25^{\circ} \mathrm{C}$ to $200^{\circ} \mathrm{C}$ [20] see Figure 3. Knowing that, the elastic-plastic behavior is also introduced in code Abaqus.

For the boundary condition, the high surface of the (CT) specimen has been loaded and a symmetry plane applied on the horizontal medium face of the specimen has been fixed by encastre constraint as shown in Figure 4. These conditions will be repeated for each length $3 \mathrm{~mm}$ on along the direction of the crack propagation of interval from 4 to $28 \mathrm{~mm}$. The modeling of crack propagation is illustrated in Figure 4.

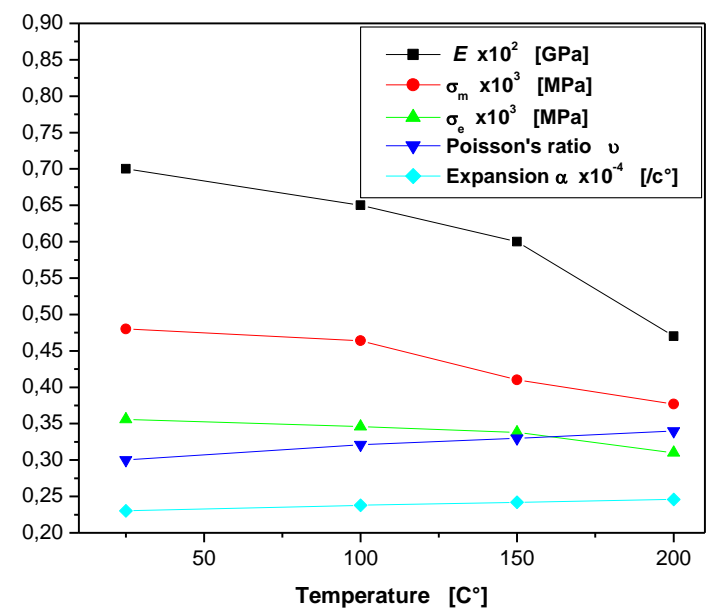

Figure 2. Material properties as a function of temperature of alloy 2024-T3 [29]

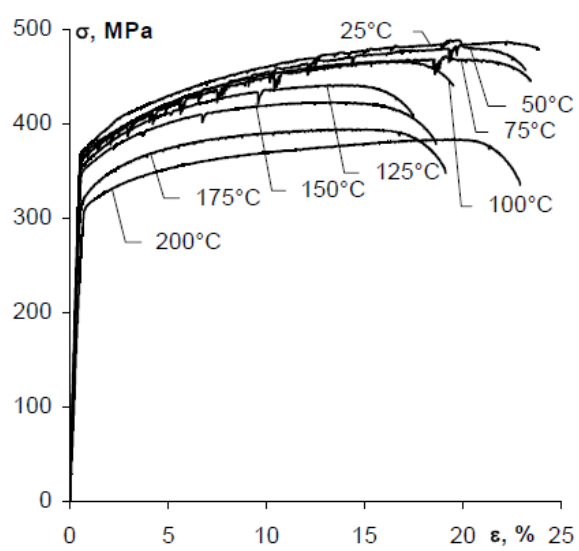

Figure 3. Chart of monotonous tensile tests of samples made of Aluminum alloy 2024-T3 for different temperatures [29]

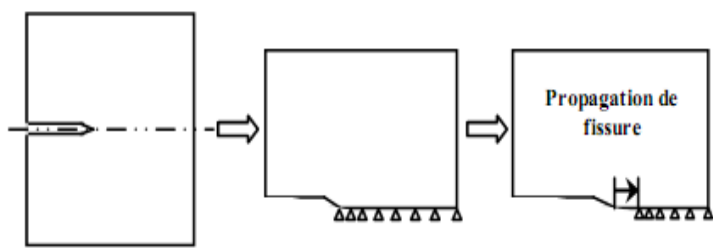

Figure 4. Modeling of crack propagation

\section{RESULTS AND INTERPRETATION}

Results of numerical analysis can be seen in Figure 5 shows the creation of the compression residual stresses $\sigma y y$ of Von Mises (direction of Mode I) when the crack front is located in the position 4 and $28 \mathrm{~mm}$ from notch for the elastic-plastic behavior proportional of a temperature $25^{\circ} \mathrm{C}$ and rate loading $\mathrm{R}=1,01$. This result has very similar tendency with other experimental studied by Song et al. [22]. 


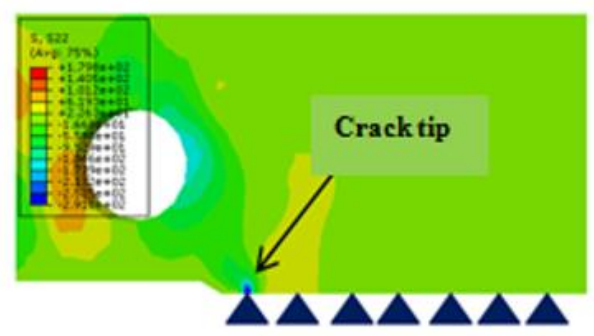

For crack length $4 \mathrm{~mm}$.

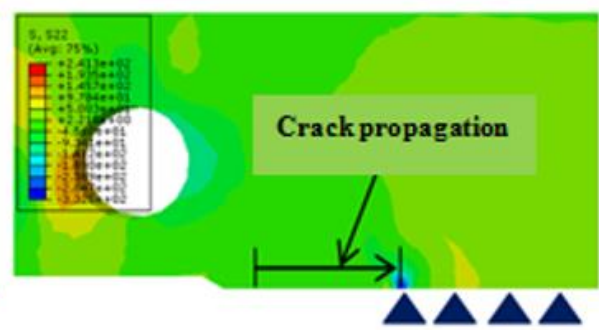

For crack length $28 \mathrm{~mm}$.

Figure 5. Distribution of Von Mises stresses $\sigma_{y y}$ at crack tip of the CT specimen

The residual stresses generations at crack tip for each length of the CT specimen are compressive in nature with decreasing absolute values as a function of the direction of the crack. The Figures 6 to 9 show the evolution of residual stresses respectively for the rates loading $\mathrm{R}=1.01$ to 1.15 at temperatures variant from 25 to $200^{\circ} \mathrm{C}$. It can be observed that in the crack tip, the residual stresses are compression stresses that change with evolution of crack. However, for each crack advance, we have remarked that the residual stresses pass a compression phase and then a tension phase away ahead of the crack, these stresses tend to zero, so there is stress relaxation. Several authors $[1,22,30]$ have been remarked the distribution of compression residual stress at crack tip.

The Figures 10 to 13 show the evolution of the residual stresses along the direction of crack propagation for temperatures variant from $25^{\circ} \mathrm{C}$ to $200^{\circ} \mathrm{C}$ which are classified according to the different rates loading. Therefore, for the same rate loading, it can be seen that the residual stresses are increase in absolute value for lower temperatures. Moreover, the low absolute values of the residual stresses are obtained for the high temperatures; this is explained by the expansion of the material. However, when, the rate loading increases, increasing in absolute value the residual stresses for the same temperature. Similar phenomena and related explanations were reported by many authors $[1,2,22,25,30]$.

Finally, for all the cases, we have noticed for the same rate loading and the same temperature as the residual stresses increase in absolute value when the crack evolves to until reaching a maximum absolute value for a length $13 \mathrm{~mm}$ then to become constant for crack length greater than this value. This phenomenon is also studied by finite element method prediction of residual stresses generation and temperature histories measurement $[8,19]$.
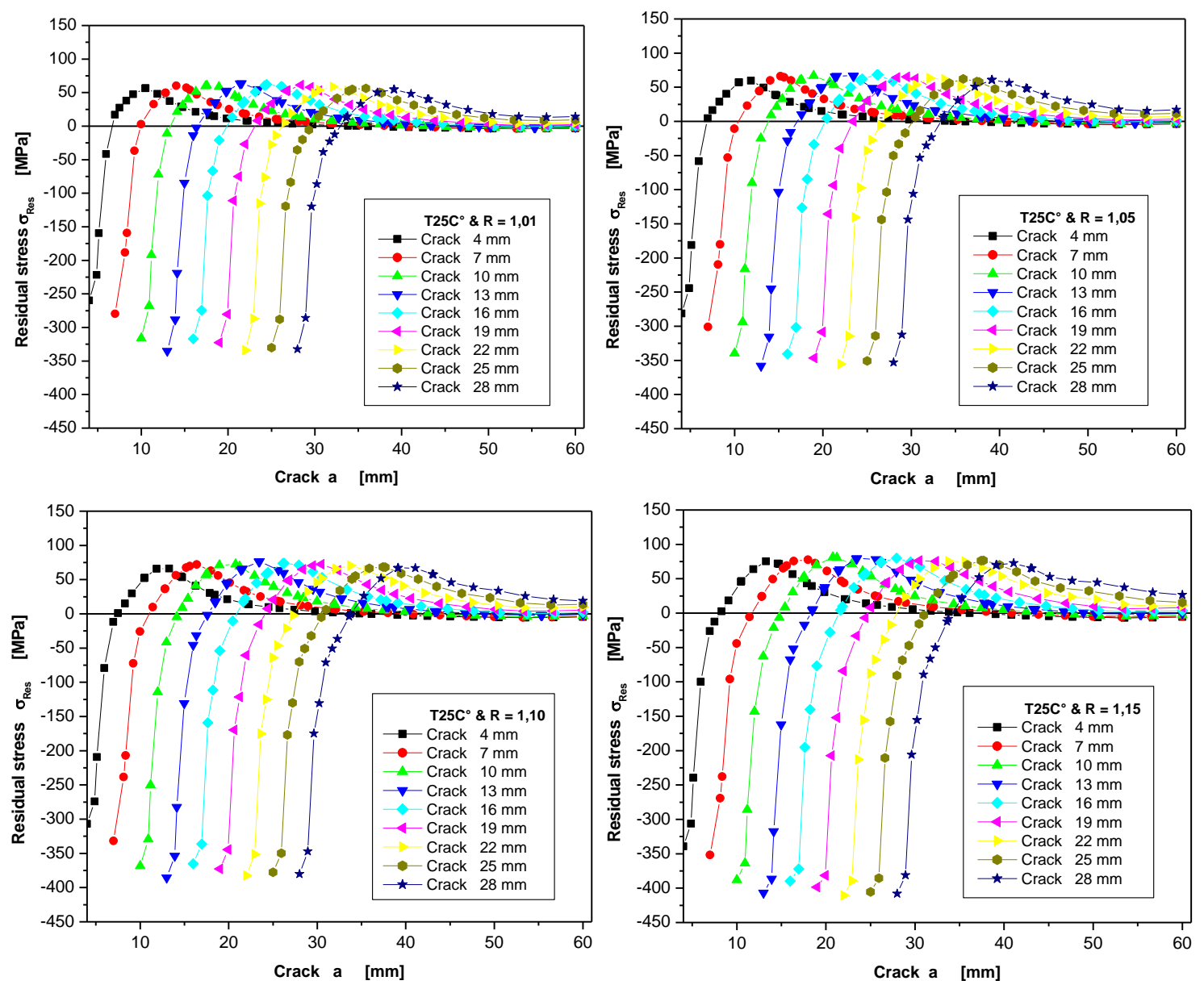

Figure 6. Distribution of residual stresses along the direction of crack propagation for different rates loading with constant temperature $\mathrm{T}=25^{\circ} \mathrm{C}$ 

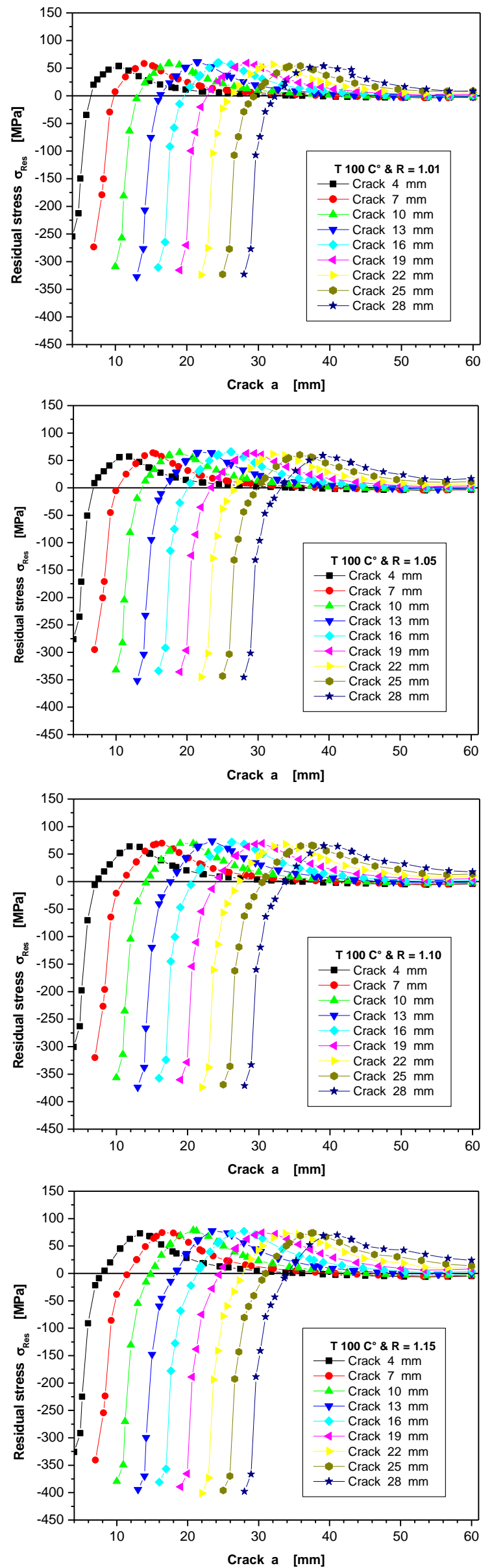

Figure 7. Distribution of residual stresses along the direction of crack propagation for different rates loading with constant temperature $\mathrm{T}=100^{\circ} \mathrm{C}$
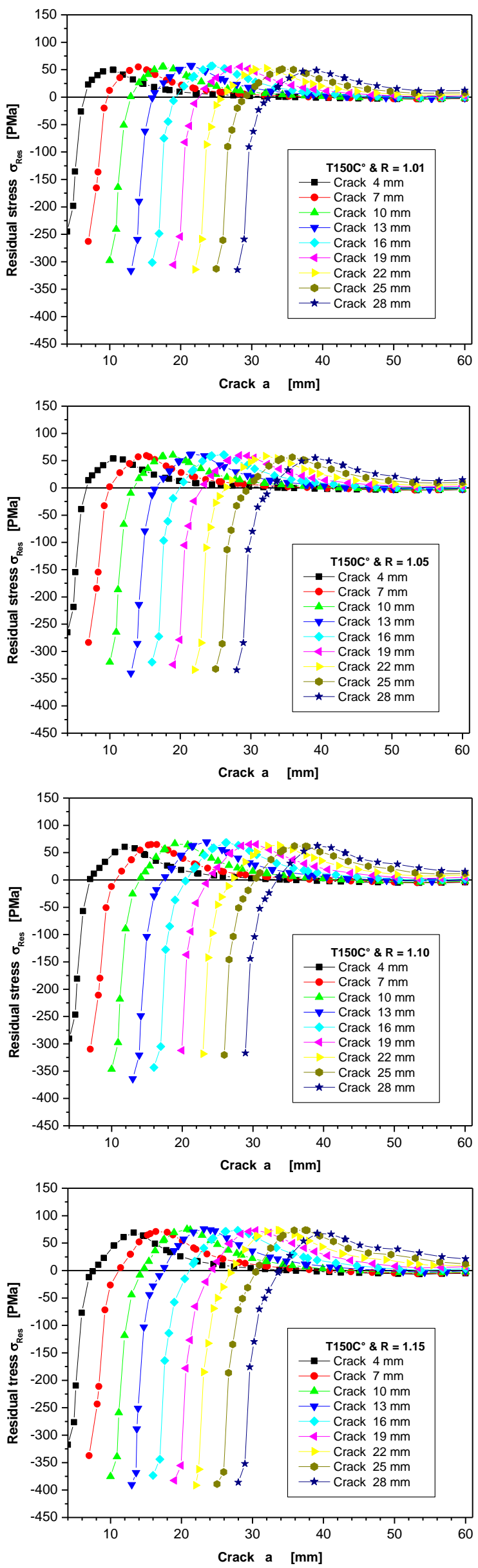

Figure 8. Distribution of residual stresses along the direction of crack propagation for different rates loading with constant temperature $\mathrm{T}=150^{\circ} \mathrm{C}$ 

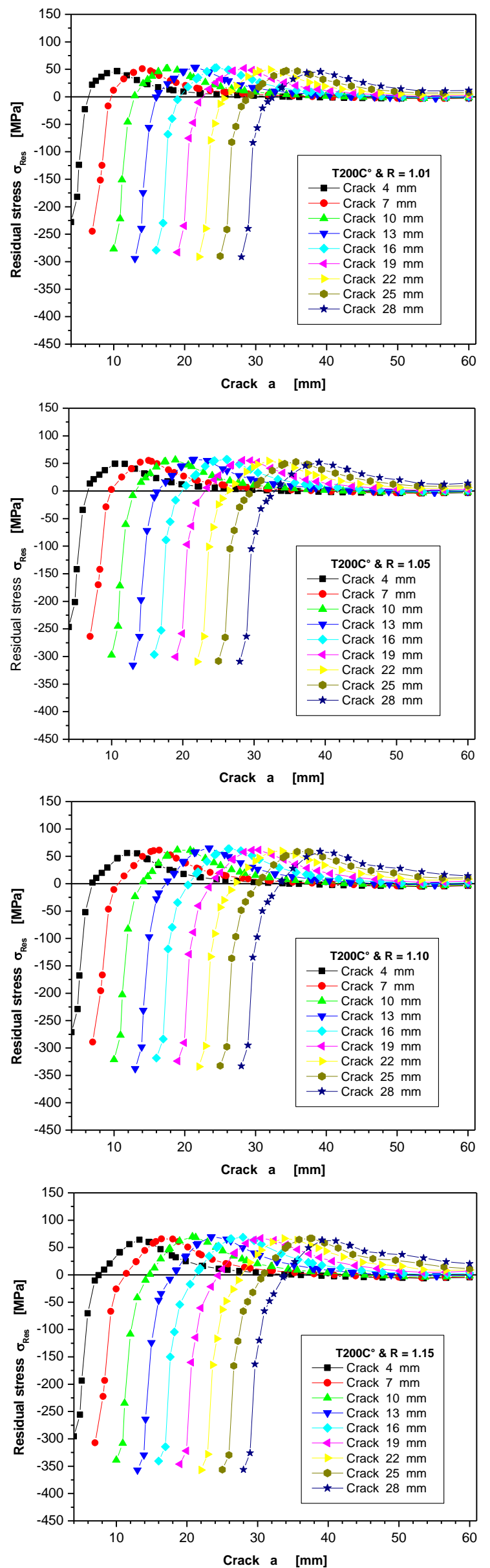

Figure 9. Distribution of residual stresses along the direction of crack propagation for different rates loading with constant temperature $\mathrm{T}=200^{\circ} \mathrm{C}$

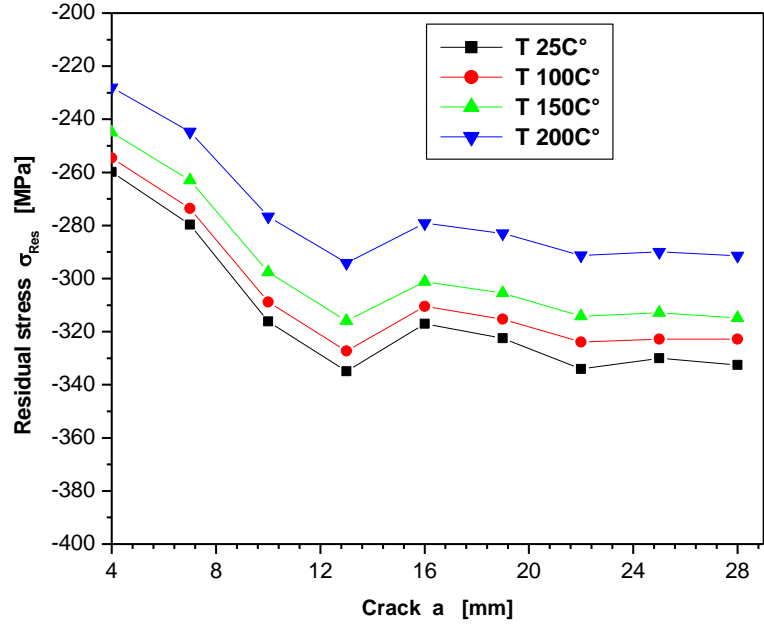

Figure 10. Evolution of the residual stresses along the direction of crack propagation for various temperatures at rate loading $\mathrm{R}=1.01$

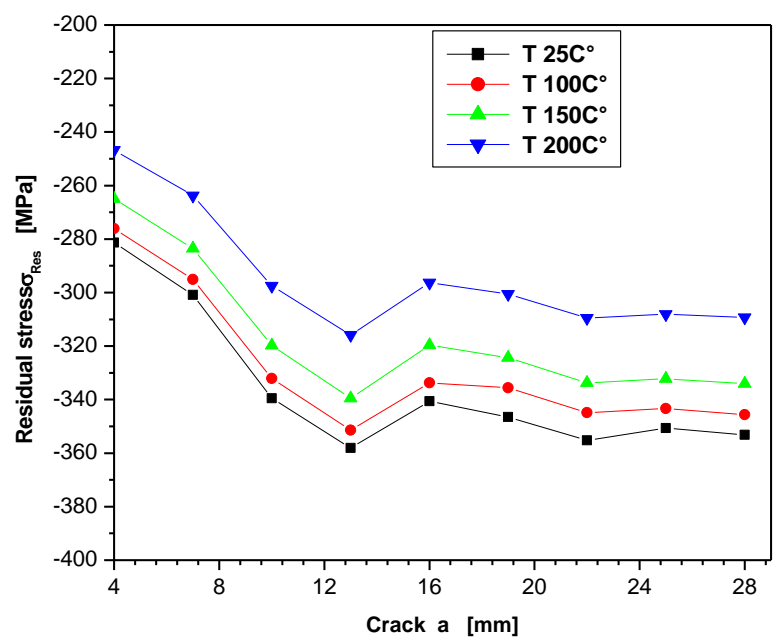

Figure 11. Evolution of the residual stresses along the direction of crack propagation for various temperatures at rate loading $\mathrm{R}=1.05$

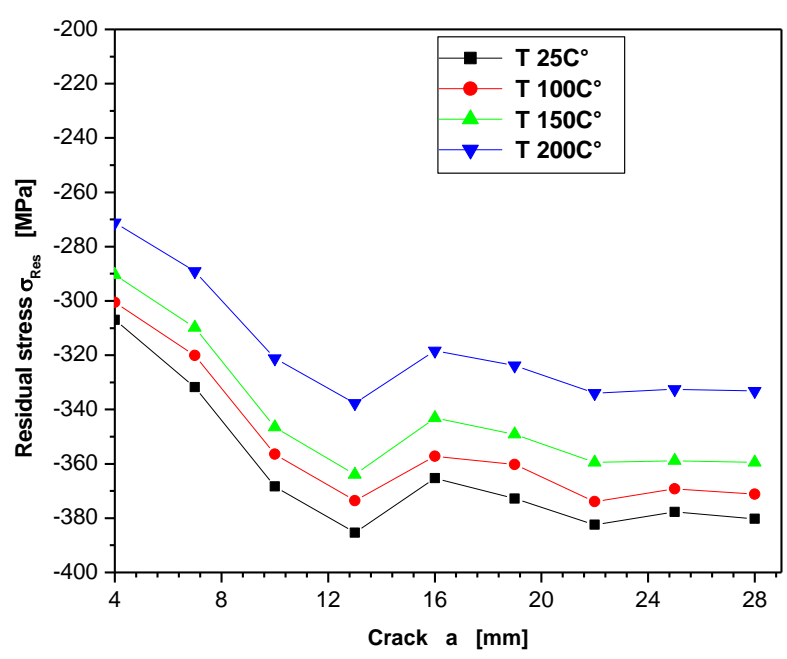

Figure 12. Evolution of the residual stresses along the direction of crack propagation for various temperatures at rate loading $R=1.10$ 


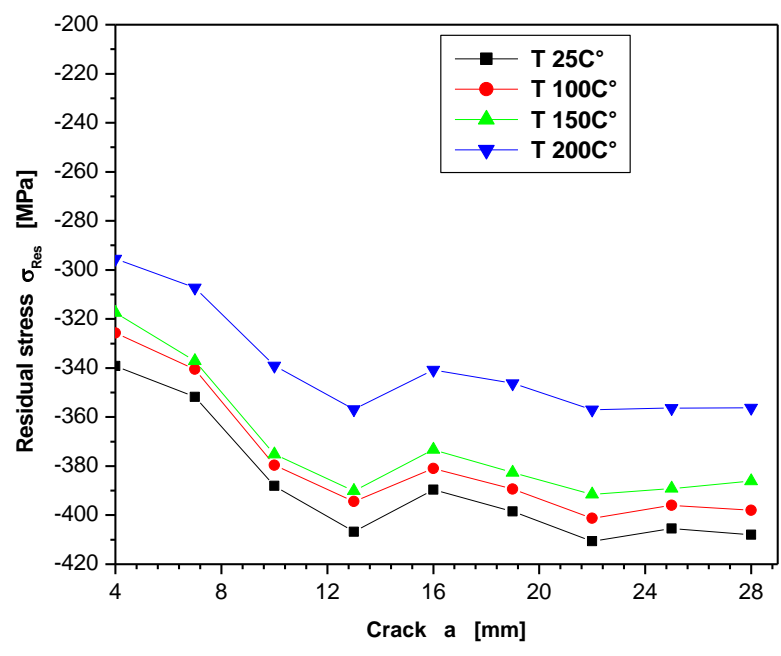

Figure 13. Evolution of the residual stresses along the direction of crack propagation for various temperatures at rate loading $\mathrm{R}=1.15$

\section{CONCLUSIONS}

The main purpose of this study, a finite element modeling technique is developed to simulate the residual stress generation at crack tip after thermomechanical effects, using an Aluminum alloy 2024-T3. The main conclusions that were drawn from this study are:

- The residual stresses at crack tip are compressive stresses that evolve with the crack propagation.

- For each crack advance, the residual stresses pass a compression phase and then a tension phase away ahead of the crack, these stresses tend to zero, so there is stress relaxation.

- The residual stresses are greater in absolute value for lower temperatures for the same rate loading.

- The low absolute values of the residual stresses are obtained for the high temperatures; this is explained by the expansion of the material.

- When the rate loading increases, the residual stresses increase in absolute value for the same temperature.

- For the same rate loading and the same temperature as the residual stresses increase in absolute value when the crack evolves to until reaching a maximum absolute value for a length $13 \mathrm{~mm}$ then to become constant for crack length greater than this value.

- The results were shown to be in good process to each other as well as experimental measurements in the literatures.

\section{REFERENCES}

[1] Seddik, R., Seddik, M., Atig, A., Fathallah, R. (2016). Thermo-mechanical relaxation of compressive residual stresses induced by shot peening. Procedia Struct. Integr., 2:

2182-2189.

https://doi.org/10.1016/j.prostr.2016.06.273

[2] Pariente, I.F., Guagliano, M. (2008). About the role of residual stresses and surface work hardening on fatigue $\Delta \mathrm{K}$ th of a nitrided and shot peened low-alloy steel. Surf. Coatings Technol., 202(13): 3072-3080. https://doi.org/10.1016/j.surfcoat.2007.11.015
[3] Yaparala, V.S., Guru Prasad, B.S., Mottedoddi Puttaswamy, H. (2016). Thermo-Mechanical Analysis Approach for Prediction of Weld Distorion and Residual Stresses on Hydro Form Structure. SAE Technical Paper Series, Tata Technologies, Ltd. https://doi.org/10.4271/2016-01-1352

[4] Lingamanaik, S.N., Chen, B.K. (2011). Thermomechanical modelling of residual stresses induced by martensitic phase transformation and cooling during quenching of railway wheels. J. Mater. Process. Technol., 211(9):

$1547-1552$ https://doi.org/10.1016/j.jmatprotec.2011.04.007

[5] Schajer, G.S. (2010). Destructive methods for measuring residual stresses: Techniques and opportunities. Experimental and Applied Mechanics, Springer, New York, NY, 6: 221-231. https://doi.org/10.1007/978-14419-9792-0_39

[6] Kaleli, T., GÜR, C.H. (2016). Non-Destructive Determination of Residual Stresses in the Spiral Submerged Arc Welded Steel Pipes. 19th World Conference on Non-Destructive Testing, pp. 1-6.

[7] Le Pécheur, A., Curtit, F., Clavel, M., Stephan, J.M., Rey, C., Bompard, P. (2012). Thermo-mechanical FE model with memory effect for 304L austenitic stainless steel presenting microstructure gradient. Int. J. Fatigue, 45: 106-15. https://doi.org/10.1016/j.ijfatigue.2012.05.016

[8] Zhu, L., Jia, M.P. (2017). A new approach for the influence of residual stress on fatigue crack propagation. Results Phys., 7: 2204-12. https://doi.org/10.1016/j.rinp.2017.06.039

[9] Huang, M., Potdar, Y.K., Akkaram, S. (2010). Analytical model to predict thermomechanical relaxation of shot peening induced residual stresses. J. Eng. Gas Turbines Power, 132(9): 92505. https://doi.org/10.1115/1.4000623

[10] Wang, J., Han, J., Li, W., Yang, Z., Li, Z., Zhao, Y. (2016). Analytical modelling of shot-peening residual stress on welding carbon steel surface layer. J. Wuhan Univ. Technol. Mater. Sci. Ed., 31(6): 1352-62. https://doi.org/10.1007/s11595-016-1538-X

[11] Stranart, J.C., Meguid, S.A., Ong, L.S., Shagal, G., Liew, K.M. (2005). Relaxation of peening residual stresses due to cyclic thermo-mechanical overload. J. Eng. Mater. Technol., 127(2): https://doi.org/10.1115/1.1867986

[12] Akbari, M., Buhl, S., Leinenbach, C., Spolenak, R., Wegener, K. (2012). Thermomechanical analysis of residual stresses in brazed diamond metal joints using Raman spectroscopy and finite element simulation. Mech. Mater., 52: 69-77. https://doi.org/10.1016/j.mechmat.2012.04.010

[13] Brosse, A., Hamdi, H., Bergheau, J. (2008). Residual stresses prediction with a new thermo mechanical simulation of grinding. Int. J. Mater. Form., 1: 1319-22. https://doi.org/10.1007/s12289-008-0146-5

[14] Lu, X., Lin, X., Chiumenti, M., Cervera, M., Li, J.J., Ma, L., Wei, L., Hu, Y., Huang, W. (2018). Finite element analysis and experimental validation of the thermomechanical behavior in laser solid forming of Ti6Al-4V. Addit. Manuf., 21: 30-40. https://doi.org/10.1016/j.addma.2018.02.003

[15] Song, Y., Wu, W., Xie, F., Liu, Y., Wang, T. (2017). A theoretical model for predicting residual stress generation in fabrication process of Double-Ceramic- 
Layer Thermal Barrier Coating System. PLoS One, 12(1): 1-20. https://doi.org/10.1371/journal.pone.0169738

[16] Weise, A., Fritsche, G. (2007). Martensitic transformation and residual stresses after thermomechanical treatment of heat treatable steel 42CrMo4 (SAE 4140). Le J. Phys. IV, 6(C1): 265-274. https://doi.org/10.1051/jp4:1996126

[17] Molano, L.C., Riera, J.M.A., Calafat, M.E. (2011). Thermo-mechanical treatment effects on stress relaxation and hydrogen embrittlement of cold-drawn eutectoid steels. Met. Mater. Int., 17(6): 899-910.

[18] Armentani, E., Esposito, R., Sepe, R. (2007). The effect of thermal properties and weld efficiency on residual stresses in welding. Manuf. Eng., 20: 319-22. https://doi.org/10.1016/S0045-7949(98)00040-6

[19] Darmadi, D.B., Tieu, A.K., Norrish, J. (2014). A validated thermo mechanical FEM model of bead-onplate welding. Int. J. Mater. Prod. Technol., 48(1-4): 14666. https://doi.org/10.1504/ijmpt.2014.059047

[20] Nishida, S.I., Zhou, C., Hattori, N., Wang, S. (2007) Fatigue strength improvement of notched structural steels with work hardening. Mater. Sci. Eng. A, 468-470: 176-83. https://doi.org/10.1016/j.msea.2006.09.120

[21] Panda, B.K., Sahoo, S. (2019). Thermo-mechanical modeling and validation of stress field during laser powder bed fusion of AlSi10Mg built part. Results Phys., 12: 1372-81. https://doi.org/10.1016/j.rinp.2019.01.002

[22] Song, H.C., Jang, C.D. (1999). Numerical modeling for the analysis of residual stress redistribution due to fatigue crack propagation. Proc. Thirteen. Asian Tech. Exch. Advis. Meet. Mar. Struct., CiteSeer ${ }^{\mathrm{X}}$.

[23] Benachour, N., Benachour, M. (2016). R-ratio effect and crack closure model in Al-alloy. Nat. Technol., 15: 9-13.

[24] Lloyd, J.R. (1999). The effect of residual stress and crack closure on fatigue crack growth. University of Wollongong Thesis Collection, 1999.

[25] Qiang, B., Li, Y., Yao, C., Wang, X. (2018). Throughthickness welding residual stress and its effect on stress intensity factors for semi-elliptical surface cracks in a butt-welded steel plate. Eng. Fract. Mech., 193: 17-31. https://doi.org/10.1016/j.engfracmech.2018.02.016

[26] Sonne, M., Carlone, P., Hattel, J. (2017). Assessment of the contour method for 2-D cross sectional residual stress measurements of friction stir welded parts of AA2024T3-numerical and experimental comparison. Metals (Basel)., 7(11): 508. https://doi.org/10.3390/met7110508

[27] Bhatti, A.A., Barsoum, Z., Murakawa, H., Barsoum, I. (2015). Influence of thermo-mechanical material properties of different steel grades on welding residual stresses and angular distortion. Mater. Des., 65: 878-889. https://doi.org/10.1016/j.matdes.2014.10.019

[28] Alderliesten, R., Lotz, T., Benedictus, R., Garcia, C., Martinez, M., Artemev, A. (2016). Fatigue crack growth in residual stress fields. Int. J. Fatigue, 87: 326-38. https://doi.org/10.1016/j.ijfatigue.2016.02.020

[29] Lipski, A., Mrozinski, S. (2012). The effects of temperature on the strength properties of aluminium alloy 2024-T3. Acta Mech. Autom., 6(3): 62-66.

[30] Xu, Y.Q., Li, S.J., Zhang, T., Yang, X.H. (2009). Research on cutting residual stresses based on thermomechanical coupling. Mater. Sci. Forum, 628629(106721340): https://core.ac.uk/display/79923257
651-656. 